PENGARUH EDUKASI TERHADAP PERSONAL HYGIENE

LANSIA DI BANJAR PEMALUKAN DESA PEGUYANGAN

\title{
The Influence of Personal Hygiene Education in Elderly At Banjar Pemalukan Desa Peguyangan
}

\author{
Desi Nopitasari ${ }^{1}$, AA Istri Putra Kusumawati ${ }^{2}$, Ika Setya Purwanti ${ }^{1}$ \\ ${ }^{1}$ STIKes Wira Medika PPNI BALI ${ }^{1}$ \\ ${ }^{2}$ RSUP Sanglah Denpasar ${ }^{2}$
}

\begin{abstract}
ABSTRAK
Pendahuluan : Personal Hygiene merupakan suatu hal yang sangat penting dalam pencegahan suatu penyakit. Personal Hygiene pada lansia yang meliputi personal hygiene pada kulit, kuku tangan dan kaki, rambut, mulut dan gigi, dan pada alat kelamin. Untuk mendapatkan personal hygiene yang baik dan benar dibutuhkan suatu pengetahuan yang baik. Tujuan penelitian ini adalah untuk mengetahui pengaruh edukasi terhadap personal hygiene lansia di Banjar Pemalukan Desa Peguyangan pada tahun 2017. Metode : Penelitian ini menggunakan rancangan penelitian Pretest-Post test dalam satu kelompok (One group Pre-post test Design). Jumlah sampel sebanyak 43 orang lansia di Banjar Pemalukan Desa Peguyangan. Hasil : Hasil penelitian menunjukkan bahwa sebelum diberikan edukasi tentang personal hygiene didapatkan 7 lansia yang kurang personal hygiene, dan 36 yang cukup. Dan setelah diberikan edukasi didapatkan personal hygiene yang baik 16 lansia dan yang cukup 27 lansia. Diskusi : Berdasarkan hasil uji Wilcoxon Signed Rank Test diperoleh nilai $p$ value sebesar 0,000 artinya ada pengaruh edukasi terhadap personal hygiene lansia di Banjar Pemalukan Desa Peguyangan.
\end{abstract}

\section{Kata Kunci: Edukasi, Personal Hygiene}

\section{ABSTRACT}

Introduction : Personal Hygiene is very important for prevention diseases, Personal Hygiene in Elderly, including hair, mouth and teeth, and genetalia. To 
get a good and right Personal Hygiene, needs good knowledge. The purpose of this research is to know The Influence of Education to Personal Hygiene elderly at Banjar Pemalukan Desa Peguyangan in 2017. Method :This research use One Group Pre-Post test Design. Total sample is about 43 elderly at Banjar Pemalukan Desa Peguyangan. Result : The result of the research shows that before researcher give the Personal Hygiene Education, gets 7 elderly that less knowledge about the Personal Hygiene, and 36 elderly that has enough knowledge about the Personal Hygiene. After researcher give the Personal Hygiene Education, gets 7 elderly that still enough knowledge about the Personal Hygiene and 27 elderly that has better knowledge about the Personal Hygiene. The result of the behavior after researcher give the education, 16 elderly shows good behavior personal hygiene. Discussion : Based on Wilcoxon Signed Rank Test gets $p$-value $=0.000$ means that there are an influence of Personal Hygiene Education in elderly At Banjar Pemalukan Desa Peguyangan .

Key Words: Education, Personal Hygiene

\begin{tabular}{ll}
\hline Alamat & $:$ STIKes Wira Medika Bali, Jl Kecak no.9A Gatot \\
Korespondensi & Subroto Timur \\
Email & $:$ davyathaa@gmail.com \\
\hline
\end{tabular}




\section{PENDAHULUAN}

Lanjut usia adalah seseorang yang mencapai usia 60 tahun ke atas, lansia adalah periode mencapai kemunduran fisik sejalan dengan waktu. Lansia merupakan kelompok usia yang mengalami penurunan personal hygiene karena dipengaruhi oleh faktor usia (Tirtana, 2011). Proses penuaan (aging process) yang merupakan suatu proses menghilangnya secara perlahan-lahan kemampuan jaringan untuk memperbaiki diri dan mempertahankan fungsi normalnya, sehingga tidak dapat bertahan terhadap infeksi dan memperbaiki kerusakan yang diderita (Bandiyah, 2009).

Permasalahan yang berkaitan dengan lansia terutama pada pemeliharaan kebersihan diri yang mencakup kebersihan rambut, kuku, mulut, dan organ tubuh lainnya. Penurunan fungsi tubuh pada lansia dapat mempengaruhi dan mengakibatkan perubahan kecil yang terjadi dalam kemampuan lansia yaitu perubahan fisik, perubahan mental, dan psikososial, sehingga mempunyai dampak ataupun sebab untuk meningkatkan kepercayaan pada lansia dan mengalami kemunduran peranan sosialnya, dan mengakibatkan timbul gangguan di dalam yang mencakupi kebutuhan hidupnya, khusunya kebutuhan kebersihan diri (Sudarsih \& Sandika, 2016).

Personal hygiene dipengaruhi oleh faktor pribadi, sosial dan budaya. masalah kebersihan kurang diperhatikan pada lansia, terjadi karena lansia menganggap masalah kebersihan adalah masalah tidak penting, padahal dapat terjadi suatu penyakit dan mempengaruhi kesehatan. Selain itu yang berhubungan dengan personal hygiene adalah gangguan kebutuhan rasa nyaman, kebutuhan dicintai, kebutuhan harga diri, aktualisasi diri dan gangguan interaksi sosial (Muko, 2014).

Edukasi kesehatan merupakan program kesehatan yang dirancang untuk mempengaruhi individu, dan masyarakat, sehingga berfikir, bersikap, dan berperilaku positif tujuannya untuk meningkatkan kesehatan, edukasi kesehatan adalah upaya untuk memelihara, meningkatkan, dan kesehatan diri dan lingkungan. Secara umum edukasi kesehatan bertujuan untuk mengembangkan perilaku individu, kelompok, atau masyarakat agar bisa berperilaku hidup bersih dan sehat, dan terhindar dari penyakit, dimana dalam pemberian edukasi personal 
hygiene pada lansia dapat meningkatkan kebersihan diri dengan baik, jika tidak ada penyuluhan diberikan edukasi tentang personal hygiene lansia masalah yang terjadi salah satunya adalah kuku tangan dan kuku kaki kotor yang menyebabkan suatu infeksi (Kholid,2014). Pentingnya edukasi dalam keperawatan, agar masyarakat memiliki mutu kehidupan yang kuat untuk menjaga kesehatanya,dan memelihara kebersihan diri dengan baik, edukasi dilakukan dalam personal hygiene 3 kali dalam sebulan (Putri \&Sirait, 2014). Kebersihan diri mempengaruhi kenyamanan, keamanan dan kesejahteraan lansia. Perawatan diri lansia ditentukan dan diberikan perawatan hygiene yang sesuai kebutuhan (Iswantiah, 2012).

Fenomena keperawatan gerontik adalah tindakan terpenuhinya kebutuhan dasar manusia sebagai akibat proses penuaan pada lansia. Berdasarkan fenomena yang terjadi lansia jika sendiri dirumah tanpa ada keluarga atau kurang dukungan dari keluarga yang akan menyebabkan lansia tidak memperhatikan kebersihan diri. (Hadi, 2009). Personal hygiene merupakan kebutuhan dasar manusia yang harus terpenuhi, personal hygiene menjadi bagian yang terpenting mengarah pada personal hygiene yang baik akan meminimalkan kuman mikroorganisme yang ada dimana-mana dan pada akhirnya mencegah seseorang terkena penyakit (Nofrianda, 2014).

Berdasarkan informasi Kemenkes RI 2014, penduduk lansia 60 tahun keatas di Indonesia dan dunia pada tahun 2013, dan pada tahun 2050, peningkatan jumlah lansia tahun 2013, 8,9\% di Indonesia, dan 13,4\% di dunia hingga tahun 2050 (21,4\% di Indonesia dan 25,3\% di dunia). (Sudarsih \& Sandika, 2016). Di Provinsi Bali jumlah penduduk lansia yang berumur $>60$ tahun pada tahun 2015 mencapai 517.500 jiwa (Rismawati, 2015).

Berdasarkan data di Dinas Kesehatan Kota Denpasar terutama Wilayah Denpasar Utara jumlah lansia pada tahun 2016 mencapai 3651 lansia. Pada tahun 2015 tercatat lansia yang mengalami sakit karena penyakit kulit alergi $(54,9 \%)$, penyakit kulit karena suatu infeksi $(29,3 \%)$, infeksi pada saluran pencernaan (15,8\%). Dari Studi pendahuluan pada tanggal 2 Februari 2017, menurut data Dinas Kesehatan Kota Denpasar tahun 2016, untuk wilayah banjar pemalukan desa peguyangan didapati 90 orang lansia dimana $76(84,44 \%)$ lansia dengan 
personal hygiene yang rendah mengalami penyakit kulit gatal-gatal, jamur dan infeksi. Sedangkan jumlah lansia yang mempunyai personal hygiene yang cukup baik ada $14(15,56 \%)$ lansia. Penyakit yang paling sering diderita oleh lansia di desa tersebut adalah penyakit kulit (dermatitis atau gatal-gatal, dan jamur pada tubuh (35\%). Dan di banjar pemalukan desa peguyangan belum pernah mendapatkan penyuluhan kesehatan terkait dengan personal hygiene, dan berdasarkan hasil wawancara dan observasi dari 10 orang lansia di dapatkan personal hygiene yang rendah $70 \%$ lansia kurang memahami tentang cara personal hygiene yang baik dan benar, dan 30\% lansia memahami pentingnya personal hygiene, sedangkan dari observasi dari 10 orang lansia akibat dari personal hygiene yang kurang ditemui penyakit kulit seperti jamur pada tubuh (25\%), karies pada gigi (15\%),dan lansia yang sehat personal hygiene yang cukup baik $(5 \%)$, sedangkan personal hygiene yang rendah yang di banjar pemalukan terlihat kuku tangan dan kaki panjang dan kotor (30\%),) berjalan tanpa menggunakan alas kaki di halaman rumah (20\%), rambut lansia kotor dan berketombe $(5 \%)$.

Tujuan dari penelitian ini adalah Mengidentifikasi personal hygiene lansia sebelum diberikan edukasi kesehatan di Banjar Pemalukan Desa Peguyangan. Mengidentifikasi personal hygiene sesudah diberikan edukasi kesehatan di Banjar Pemalukan Desa Peguyangan. Menganalisa apakah ada pengaruh edukasi kesehatan terhadap peningkatan personal hygiene.

\section{METODE PENELITIAN}

Penelitian ini merupakan penelitian kuantitatif dengan jenis penelitian

yang dilakukan adalah Pra Eksperimen. . Rancanga dalam penelitian ini menggunakan rancangan penelitian Pre test-Post test dalam satu kelompok (One group Pre-post test Design). Populasi dalam penelitian ini adalah lansia di Banjar Pemalukan Desa Peguyangan sebanyak 76 orang lansia personal hygiene rendah.

Sampel terdiri atas bagian populasi terjangkau yang dapat dipergunakan sebagian subjek penelitian melalui sampling (Nursalam, 2016). Sampel dalam penelitian. Sampel yang akan digunakan dalam penelitian ini adalah 43 orang lansia yang tinggal di Banjar pemalukan Desa Peguyangan. 
Penulis merasa tertarik menjadikan sebagai tempat penelitian karena terdapat banyak lansia yang mengalami personal hygiene rendah. Penelitian dilaksanakan pada bulan April sampai Mei 2017.

Penelitian ini menggunakan kuesioner dan lembar observasi prosedur pemberian edukasi personal hygiene. Analisis Bivariat bertujuan untuk mengetahui perbedaan sebelum dan setelah diberikan edukasi pada lansia. Mengingat data kelompok yang tersedia (data pre test dan post test merupakan sampel kelompok berpasangan dengan skala nominal dan ordinal, maka untuk memperoleh hasil yang signifikan dalam penelitian ini menggunakan uji "Wilcoxon Signed Rank".

\section{HASIL}

Tabel 1. Hasil identifikasi personal hygiene pada lansia sebelum (pre) diberikan edukasi. Hasil identifikasi personal hygiene pada lansia sebelum diberikan edukasi di Banjar Pemalukan Desa Peguyangan Denpasar

\begin{tabular}{lllll}
\hline $\begin{array}{l}\text { Kategori } \\
\text { Personal } \\
\text { Hygiene }\end{array}$ & Frequency & Percent & $\begin{array}{l}\text { Valid } \\
\text { Percent }\end{array}$ & $\begin{array}{l}\text { Cumulative } \\
\text { Percent }\end{array}$ \\
\hline Baik & 0 & 0 & 0 & 0 \\
\hline Cukup & 36 & 83,7 & 83,7 & 100 \\
\hline Kurang & 7 & 16,3 & 16,3 & 16,3 \\
\hline Total & 43 & 100 & 100 & \\
\hline
\end{tabular}

Dari hasil pre post pada lansia sebelum diberikan pemberian edukasi tentang personal hygiene di dapatkan nilai 7 kurang (16,3\%), cukup 36 (83,8\%).

Tabel 2. Hasil Identifikasi personal hygine lansia sesudah (post) diberikan edukasi. Hasil identifikasi personal hygiene lansia sesudah diberikan edukasi di Banjar Pemalukan Desa Peguyangan Denpasar 


\begin{tabular}{lllll}
\hline $\begin{array}{l}\text { Kategori } \\
\text { Personal } \\
\text { Hygiene }\end{array}$ & Frequency & Percent & $\begin{array}{l}\text { Valid } \\
\text { Percent }\end{array}$ & $\begin{array}{l}\text { Cumulative } \\
\text { Percent }\end{array}$ \\
\hline Baik & 16 & 37,2 & 37,2 & 100 \\
\hline Cukup & 27 & 62,8 & 62,8 & 62,8 \\
\hline Kurang & 0 & 0 & 0 & 0 \\
\hline Total & 43 & 100 & 100 & \\
\hline
\end{tabular}

Dari hasil post test didapatkan hasil pada lansia setelah diberikan edukasi, personal hygiene yang baik 16 lansia (37,2\%), yang cukup 27 lansia $(62,8 \%)$ dan yang kurang tidak ada.

Tabel 3. Hasil Analisis Pengaruh Edukasi Personal Hygiene Lansia di Banjar Pemalukan Desa Peguyangan.

\begin{tabular}{lllll}
\hline $\begin{array}{l}\text { Pemberian edukasi personal hygiene } \\
\text { pada lansia }\end{array}$ & Jumlah & $\begin{array}{l}\text { Mean } \\
\text { Rank }\end{array}$ & $\begin{array}{l}\boldsymbol{p} \\
\text { value }\end{array}$ \\
\hline Negatif ranks & 0 & 0 & - & 0,000 \\
& & & 4.796 & \\
Positif ranks & 23 & 12,00 & & \\
Ties & 20 & & & \\
\hline Total & 43 & & & \\
\hline
\end{tabular}

\section{PEMBAHASAN}

Menurut Wawan dan Dewi (2010), mengukapkkan seiring bertambahnya tingkat pendidikan maka bertambah pula pengalaman yang dimiliki oleh seseorang sehingga pengetahuan orang juga akan bertambah, berdasarkan hasil penelitian yang diperoleh sebagian besar responden berumur 60-74 (90,9\%) yang didapatkan sehingga umur yang matang secara relatif juga mempengaruhi pengetahuan seseorang. 
Hasil penelitian yang juga didapatkan oleh Nuradawiyah (2012), yang berjudul hubungan pengetahuan, sikap dengan praktik kebersihan kulit pada lansia di Unit Rehabilitasi Sosial Wening Wardoyo Ungaran yang mengungkapkan dari 49 responden, yang memiliki pengetahuan baik sebanyak 18 responden $(36,7 \%)$ dan yang memiliki pengetahuan kurang sebanyak 31 responden $(63,3 \%)$.

Penelitian Iswantiah (2012) yang berjudul Pendidikan Kesehatan Terhadap Perilaku Kesehatan Lansia Tentang Personal Hygiene yang mengungkapkan dari 30 responden pendidikan kesehatan perilaku baik meningkat menjadi 86,7\%), dan perilaku yang cukup $(13,3 \%)$, dan observasi perilaku dari setelah diberikan perlakuan didapatkan 30 lansia 69,8\% baik dan 13 lansia 30,3\% perilaku yang cukup.

Hasil dalam penelitian ini sejalan dengan penelitian yang dilakukan oleh Rina (2014), perilaku lansia sebagian besar baik sebanyak 42 responden $(65,6 \%)$ dan cukup sebanyak 22 responden $(34,4 \%)$. Hasil penelitian yang berbeda didapatkan oleh Mulyono (2012), perilaku personal hygiene sebagian besar sebanyak 60 responden $(85,7 \%)$, perilaku personal hygiene cukup sebanyak 10 responden (14,3\%) dan hasil penelitian didapatkan oleh Indriyani (2012), yang menunjukkan bahwa dari 63 responden, 60 responden yang berperilaku baik dan 3 responden berperilaku cukup. Faktor yang mempengaruhi seseorang dalam melakukan personal hygiene, antara lain body image, pengetahuan, praktik sosial, kondisi fisik, kebiasaan, budaya dan status sosial ekonomi (Suciati, 2014). Pengetahuan penting dalam mengubah perilaku manusia. Bahwa Notoatmodjo (2012) mengemukakan pengetahuan merupakan salah satu faktor internal yang dapat mempengaruhi perilaku seseorang. Pengetahuan responden dipengaruhi oleh faktor umur, pendidikan, dan pekerjaan, sedangkan perilaku responden selain dipengaruhi oleh pengetahuan juga dipengaruhi adanya motivasi dalam dirinya. Pendidikan dan pekerjaan telah memberikan wawasan yang luas sehingga seseorang akan mampu meningkatkan pengetahuannya untuk menghadapi masalah kesehatan yang dihadapi. Pendidikan yang dimaksudkan bukan hanya pendidikan formal saja, tetapi juga pendidikan nonformal di tempat - tempat umum seperti penyuluhan di masyarakat, rumah sakit atau media masa sehingga pengetahuan tentang personal hygiene dengan perilaku lansia dalam pemenuhan 
personal hygiene dapat dilakukan secara maksimal. Dengan belajar individu diharapkan mampu menggali apa yang terpendam dalam dirinya dengan mendorong untuk berpikir dan mengembangkan kepribadiannya dengan membebaskan diri dari ketidaktahuannya. Dari hasil persepsi peneliti dapat menyimpulkan bahwa pengetahuan yang baik akan membantu seseorang untuk memahami, mengaplikasikan dan menganalisa setiap perilaku secara baik pula. Perilaku seseorang tidaklah dapat dipisahkan dengan tingkat pengetahuan orang tersebut, terlebih lagi dalam kaitannya dengan perilaku kesehatan yang terkadang masih merupakan sesuatu yang sangat awam bagi sebagian kalangan masyarakat.

Hasil penelitian Iswantiah (2012) yang meneliti tentang Pendidikan Kesehatan Terhadap Perilaku Kesehatan Lansia Tentang Personal Hygiene di daerah Sleman Yogyakarta menjelaskan bahwa jumlah sampel yaitu 30 responden yang dibagi menjadi dua kelompok. Hasil penelitian ini yaitu pada kelompok eksperimen setelah diberikan pendidikan kesehatan perilaku baik meningkat menjadi (86,7\%), perilaku cukup $(13,3 \%)$ dan perilaku kurang tidak ada. Peningkatan perilaku pada kelompok eksperimen ditunjukkan dengan nilai signifikansi $\mathrm{P}=0,001$ dan pada kelompok kontrol tidak ada perubahan yang signifikansi dengan nilai $\mathrm{P}=0,655$. Sehingga didapatkan hasil yaitu ada pengaruh pendidikan kesehatan terhadap perilaku kesehatan lansia tentang personal hygiene lansia.

Zamzami (2012) meneliti tentang Pengaruh Penyuluhan Kesehatan Personal Hygiene Terhadap Pengetahuan Personal Hygiene Pada Lansia di Panti Tresna Werda Kabupaten Cianjur dengan responden 65 lansia yang dibagi dua kelompok. Berdasarkan uji statistik dengan Wilcoxon nilai $\mathrm{Z}$ hitung $<\mathrm{Z}$ tabel ($5.916<-1,96)(2$-tailed $)=0,000$. Oleh karena nilai Asymp. Sig. (2-tailed) lebih kecil dibandingkan 5\% $(0,000<0,05)$ maka terdapat pengaruh penyuluhan kesehatan personal hygiene pada lansia di Panti Tresna Werdha Kabupaten Cianjur. Ini menunjukkan bahwa manfaat penyuluhan kesehatan dapat mempengaruhi pengetahuan seseorang, dengan hasil tersebut, penyuluhan kesehatan yang dilakukan sebanyak 3 kali selama 3 hari berturut - turut dapat mempengaruhi pengetahuan pada lansia terkait personal hygiene. Hasil dari statistik secara teoritis pengaruh penyuluhan kesehatan terhadap pengetahuan 
pada lansia terbukti ada pengaruhnya yaitu dengan melihat hasil nilai rata - rata pengetahuan personal hygiene pada lansia sebelum dan setelah penyuluhan kesehatan yang mengalami peningkatan pengetahuan sebanyak 0,54 dari 0,17 menjadi 0.71. Sehingga dengan melakukan penyuluhan kesehatan selama 3 hari berturut - turut sebanyak 3 kali dapat meningkatkan pengetahuan lansia.

Berdasarkan hasil persepsi penelitian dapat disimpulkan bahwa pemberian edukasi terkait dengan personal hygiene dapat meningkatkan suatu pengetahuan pentingnya menjaga dan merawat kebersihan diri dan perilaku lansia yang menjadi lebih baik serta bermanfaat untuk kesehatan lansia sendiri. Maka dapat disimpulkan pemberian edukasi berpengaruh dalam meningkatkan pengetahuan lansia dan mengubah perilaku menjadi yang baik pada lansia.

\section{SIMPULAN DAN SARAN}

\section{Simpulan}

Sebelum diberikan perlakuan edukasi tentang personal hygiene lansia didapatkan nilai pre post personal hygiene yang kurang 7 (16,3\%), dan yang cukup $36(83,7 \%)$, dan yang baik tidak ada. Setelah diberikan perlakuan edukasi tentang personal hygiene lansia didapatkan nilai post test personal hygiene yang baik $16(37,2 \%)$, cukup 27 (62,8\%), dan yang kurang tidak ada. Dari hasil analisa diperoleh $p$ value sebesar $0,000<0,05$ ini berarti ada pengaruh edukasi personal hygiene terhadap lansia di Banjar Pemalukan Desa Peguyangan.

\section{Saran}

Bagi tenaga kesehatan perlu ditingkatkan dalam hal pemberian informasi melalui penyuluhan tidak hanya kepada lansia saja melainkan kepada keluarganya. Perlu diperhatikan media dalam hal memberikan penyuluhan yaitu menggunakan media AVA (Audio Visual Aids) pada kegiatan posyandu lansia agar pesan yang disampaikan dapat diterima dengan baik, sehingga diharapkan pengetahuan lansia menjadi meningkat.

Bagi peneliti selanjutnya diharapkan untuk mengembangkan faktor-faktor yang mempengaruhi personal hygiene seperti budaya, body image ,pengetahuan, 
status sosial ekonomi.Di samping agar menggunakan kelompok kontrol, sehingga hasil yang diperoleh lebih valid

\section{KEPUSTAKAAN}

Abdurachim, dkk. 2016. Hubungan Asupan Natrium, Frekuensi dan Durasi Aktivitas Fisik terhadap Tekanan Darah Lansia di Panti Sosial Tresna Werdha Budi Sejahtera dan Bina Laras Budi Luhur Kota Banjarbaru, Kalimantan Selatan. GIZI INDONESIA.39 (1) : pg. 37-48.

Almasyah dan Muliawati. 2013. Pilar Dasar Ilmu Kesehatan Masyarakat.Yogyakarta:Nuha Medika.

Arikunto, S. 2010. Prosedur Penelitian Suatu Pendekatan Praktek.Jakarta: Rineka Cipta.

Azwar, 2012. Reliabilitas dan Validitas, Yogyakart Available: http://digilib.unila.ac.id.(29Juni 2017)

Bandiyah, S. 2009. Lanjut Usia dan Keperawatan Gerontik. Yogjakarta : Nuha Medika

Dinas Kesehatan Kota Denpasar 2016. Data penduduk lansia Kota Denpasar

Gayatri. 2013. Hubungan Tingkat Pengetahuan tentang Personal Hygiene dengan Perilaku Lansia di Kecamatan Toko Tengah Padang. Available : http://jurnal.fk.unand.ac.id. (1 April 2017).

Kholid, A. 2014. Promosi Kesehatan Dengan Pendekatan Teori Perilaku, Media, dan Aplikasinya. Ed. 2, Jakarta: PT RajaGrafindo Persada

Hadi, M. 2009. Buku Ajar Boedhi Darmojo Geriarti. Jakarta: FKUI

Indriyani. 2012. Hubungan Pengetahuan tentang Personal Hygiene dengan Perilaku Personal Hygiene Lansia. Available : http://jurnal.fk.unand.ac.id. (12 Februari 2016).

Iswantiah, dkk. 2012. Pendidikan Kesehatan Terhadap Perilaku Kesehatan Lansia Tentang Personal Hygiene. Jurnal Keperawatan, Yogyakarta, 3 (2) :pg. 152-158.

Mahrifatulhijah.2012. Kebutuhan Personal Hygiene. JKem-U, Surakarta, 4 (10): pg. $50-53$. 
Muko.2014. Perbedaan Personal Hygiene Pada Lansia Di Panti Sosial Tresna Werdha Ilomata dan Beringin Provinsi Gorontalo. Jurnal KIM Fakultas Ilmu Kesehatan 1 (2).

Mulyono. 2014. Hubungan antara Pengetahuan Lansia tentang Personal Hygiene dengan Perilaku Personal Hygiene Lansia di Kelurahan Biyonga. Available : http:// repository.eniusu.ac.id (26 Juni 2017).

Muhith, A. \& Siyoto, S. 2016. Pendidikan Keperawatan Gerontik. Ed. 1, Yogyakarta: CV ANDI OFFSET.

Nofrianda, M. 2014. Pengetahuan dan Sikap Lansia dalam Melakukan Personal Hygiene di UPT Pelayanan Sosial Lanjut Usia Skripsi Fakultas Keperawatan Universitas Sumatera. Avaiable: http://repository.usu.ac.id (3 Februari 2017).

Notoatmodjo, S. 2012. Ilmu Perilaku Kesehatan. Jakarta: PT RINEKA CIPTA 2014. Promosi Kesehatan dan Perilaku Kesehatan. Jakarta : Rineka Cipta.

Nuradawiyah,dkk. 2012. Hubungan Pengetahuan Sikap dengan Praktik Kebersihan Kulit pada Lansia di Unit Rehabilitasi Sosial Wening Wardoyo Ungaran. Avaiable: jurma.unimus.ac.id (12 Februari 2017).

Nursalam. 2008. Konsep dan Penerapan Metodologi Penelitian Ilmu Keperawatan. Jakarta : Salemba Medika. Pg. 171-175 Ed. 4. . 2015. Metode Penelitian Ilmu Keperawatan.Jakarta : Salemba Medika. Pg. 172-173 Ed. 4.

_ 2016. Metodologi Penelitian Ilmu Keperawatan. Ed. 4, Jakarta: Salemba Medika.

Pinedendi, dkk. 2016. Pengaruh Penerapan Asuhan Keperawatan Defisit Perawatan Diri Terhadap Kemandirian Personal Hygiene pada Pasien di RSJ. PROF. V. L. RATUMBUYSANG MANADO. Jurnal Keperawatan. 4 (2)

Prasetio. 2015. Pengaruh Pendidikan Kesehatan terhadap Tingkat Pengetahuan dan Sikap Lansia dalam Pemanfaatan Pelayanan Kesehatan di Wilayah Kartasura. Available: http://eprints.ums.ac.id (15 Februari 2017). 
Putri, M.H. \& Sirait, T. 2014. Pengaruh Pendidikan Penyikatan Gigi dengan Menggunakan Model Rahang Dibandingkan dengan Metode Pendampingan terhadap Tingkat Kebersihan Gigi dan Mulut Siswa-siswi Tunanetra SLB-A Bandung. Jurnal MKB. 46 (3): pg. 134-142.

Ramadhan, K. \& Sabrina, I.K.A. 2016. Hubungan Personal Hygiene dengan Citra Tubuh pada Lansia di Desa Sepe Kecamatan Lage Kabupaten Poso. Jurnal Kesehatan Prima . 10 (2) : pg. 1735-1748.

Rismawati, N.L. 2015. Pemprov Bali Serius Tangani Persoalan Lansia. Available:http://www.antarabali.com(28February 2017).

Rina. 2014. Hubungan Tingkat Pengetahuan Lansia tentang Personal Hygiene dengan Perilaku Lansia di Desa Gelogor.Available: http://jurnal.unimus.ac.id. (26 Juni 2017).

Riyanto, M. 2011. Aplikasi Metodologi Penelitian Kesehatan. Ed. 1, Yogyakarta: Nuha Medika.

Savitri. 2011. Hubungan Pengetahuan Lanjut usia dengan Sikap Memelihara Kebersihan Diri pada Lansia di Kelurahan Bandungharjo Kecamatan Toroh Kabupaten Grobogan .Avaiable: https://publikasiilmiah.ums.ac.id (10 Februari 2017).

Sudarsih, S. \& Sandika, D.R. 2016. Hubungan antara dukungan keluarga dengan kemandirian lansia dalam pemenuhan personal hygiene.JurnalPenelitianKesehatan. 2 (14)

Susanto, dkk. 2015. Gambaran Skor Mmse, Cdt, Tmt A dan B Pada Lansia Di Panti Werdha Agape Tondano. Jurnal e- Clinic. 1 (3) : pg.348-351.

Sutikno, E. 2011. Hubungan Fungsi Keluarga dengan Kualitas Hidup Lansia. Surakarta. Avaiable: http://eprints.uns.ac.id (14 Februari 2017).

Sugiyono. 2015. Metode Penelitian Pendidikan Pendekatan Kuantitatif, Kualitatif, dan $R \& D$. Ed. 21, Bandung: CV. ALFABETA.

Wawan dan Dewi. 2010. Teori dan Pengukuran : Pengetahuan, Sikap, dan Perilaku Manusia. Yogyakarta : Nuha Medika.

Yulianti, U. 2013. Pendidikan kesehatan dan ilmu perilaku resume. Available: https://www.slideshare.net (4 Maret 2017).

Yuni. 2015. Personal hygiene. Yogyakarta: Nuha Medika. 
Zamzami, dkk. 2012. Pengaruh Penyuluhan Kesehatan Personal Higiene Terhadap Pengetahuan Personal Higiene Pada Lansia Di Panti Tresnawerda Kabupaten Cianjur. Jurnal Bhakti Kencana Medika, 4 (2). 